\title{
Flexibility and Functional Asymmetry in Rhythmic Gymnastics
}

\author{
By Amanda Batista ${ }^{*}$ Rui Garganta ${ }^{\dagger} \&$ Lurdes Ávila-Carvalho ${ }^{*}$
}

This study aimed to compare the flexibility level in Portuguese rhythmic gymnasts across competitive levels, investigate possible functional asymmetries in gymnasts across the competitive levels, and determine which flexibility variables better explain performance. Participants included young gymnasts $(n=157)$ in three competitive levels (Base, $1^{\text {st }}$ division and Elite), who performed ten specific passive and active flexibility tests were used. The asymmetry index was calculated and a limit of $15 \%$ bilateral difference was established as normal flexibility difference in the lower limbs. Upper and lower limbs, as well as multi-joint flexibility increased with higher competition level, although these differences were not significant between $1^{\text {st }}$ division and Elite in upper limbs and multijoint tests. All groups showed differences in passive and active flexibility between preferred and non-preferred lower limb. In addition, the higher the competition level, the lower the asymmetry level. Functional asymmetry was found in $69 \%$ and $71 \%$ of the gymnasts in passive and active flexibility, respectively. Finally, active flexibility with preferred lower limb explained $21.8 \%$ of the variance in performance with some differences in the variables explaining performance across levels.

Keywords: Rhythmic Gymnastics, Portuguese Gymnasts, Flexibility, Functional Asymmetry, Performance.

\section{Introduction}

In Rhythmic Gymnastics (RG), flexibility, strength, endurance, coordination, agility, balance and rhythm are essential to develop motor skills at a high level (Polat and Günay 2016) in order to perfectly execute body and apparatus movements (Bordalo et al. 2015). Thus, the development of gymnasts requires a particular training process and a specific theoretical and practical knowledge of the sport (Bobo-Arce and Méndez-Rial 2013).

Flexibility is one of main physical capacities that have been identified as contributing factors to performance in RG (Di Cagno et al. 2009, Douda et al. 2008, Miletić et al. 2004, Rutkauskaite and Skarbalius 2009, 2011). It is characterized by the amplitude of the movements that depends on the joint mobility expressed by the anatomical properties of the joints, and the muscle elasticity expressed by the level of stretching of the muscles (Laffranchi 2001). Rhythmic gymnasts should have

\footnotetext{
"PhD Student in Sports Sciences - FADEUP Centre of Research, Education, Innovation and Intervention in Sport (CIFI2D), Faculty of Sport, University of Porto, Portugal.

${ }^{\dagger} \mathrm{PhD}$ in Sports Science Centre of Research, Education, Innovation and Intervention in Sport (CIFI2D), Associate Professor, Faculty of Sport, University of Porto, Portugal.

${ }^{7} \mathrm{PhD}$ in Sports Science, Centre of Research, Education, Innovation and Intervention in Sport (CIFI2D), Associate Professor, Faculty of Sport, University of Porto, Portugal.
} 
high levels of flexibility, especially in the hip, scapulohumeral and spine joints (Jastrjembskaia and Titov 1999, Stadnik et al. 2010, Volpi da Silva et al. 2008). In fact, flexibility increases, even if not linearly, the possibility of executing different movements, thus, providing a higher gymnasts' technical level and consequently an improvement in competition results (Boligon et al. 2015). In contrast, insufficient flexibility hinders the performance in certain body elements (Jastrjembskaia and Titov 1999) and makes it more difficult to perfect the technique, to educate the expressiveness and to demonstrate the lightness of the movements that are essential characteristics in this sport (Lisitskaya 1995). Appropriate levels of flexibility are a precondition for proper performance of all basic body elements (jumps, balance and rotation) (Miletić et al. 2004).

$\mathrm{RG}$ aims to exercise the body bilaterally, however, in reality, to achieve high performance, the gymnast often performs repetitive motor actions only with the preferred side, which eventually encourages unilateral training (Teixeira and Paroli 2000, Zaidi 2011). Thus, despite the natural asymmetry of the human body, it is suggested that the functional asymmetry in this sport is mainly the result of training (Lisitskaya 1995). According to Lisitskaya (1995), the apparent asymmetries may reflect negatively on the physical and technical preparation of gymnasts, which in the short-term become performance conditioning factors and in the long-term can produce pathologies. The importance of this study is justified by the necessity of more information about flexibility of rhythmic gymnasts from different competition levels, functional asymmetry and predictors of performance in RG. This information is a basic element of work to RG coaches, so they can to perform organizational and intervention strategies based on specific research.

The objectives of this study were: (1) to identify and compare the flexibility level in Portuguese gymnasts across competitive levels, (2) investigate possible functional asymmetries in gymnasts across competitive levels, and (3) determine the flexibility variables that better explain RG performance.

\section{Material and Methods}

Participants: 157 Portuguese gymnasts who participated in the district and or national competitions during the 2013/2014 season, in three different levels: Base, $1^{\text {st }}$ division and Elite.

Age and Training Characteristics: chronological age, practice experience (number of years of RG training), age at the onset of training and training volume were collected using questionnaires (Table 1). 
Table 1. Age and Training Characteristics of the Sample Gymnasts

\begin{tabular}{|l|c|c|c|}
\hline Variables & Base $(\mathbf{n = 8 2})$ & $\begin{array}{c}\mathbf{1}^{\text {st }} \text { Division } \\
(\mathbf{n = 6 6})\end{array}$ & $\begin{array}{c}\text { Elite } \\
(\mathbf{n = 9})\end{array}$ \\
\hline Age (years) & $13.3 \pm 2.0$ & $13.5 \pm 2.1$ & $14.8 \pm 1.8$ \\
\hline Training volume (hours/week) & $13.9^{*} \pm 6.4$ & $18.5^{*} \pm 6.4$ & $31.2^{*} \pm 6.2$ \\
\hline RG practice (years) & $5.6^{*} \pm 3.2$ & $6.6^{*} \pm 2.6$ & $8.2^{*} \pm 1.9$ \\
\hline Age at the onset of training (years) & $7.2 \pm 2.6$ & $6.4 \pm 1.9$ & $6.0 \pm 1.5$ \\
\hline${ }^{*} p \leq 0.05$ : significant differences
\end{tabular}

Ethical Considerations: The study protocol was approved by the Ethics Committee of the Faculty of Sport, University of Porto - Portugal (CEFADE 202013) and Scientific Committee of the Portugal Gymnastics Federation. The assessments were performed in accordance with the ethical standards of the Helsinki Declaration.

Flexibility Measurements: The maximum passive and active flexibility was measured using ten specific RG movements of main joints: hip, shoulders and spine, according to the International Gymnastics Federation (FIG) recommended tests (Klentrou et al. 2010). The tests were grouped according to the anatomical region analyzed (Table 2). In brief, passive flexibility of lower limbs (LL) was assessed using leg up with help of the hand forward (PLF), sideways (PLS) and backward (PLB). LL active flexibility was assessed using leg up without help of the hand forward (ALF), sideways (ALS) and backward (ALB). Upper limb (UL) flexibility was assessed using shoulder rotation with stick in anteversion and retroversion (RUL). Multi-joint flexibility was assessed lying on the floor (face down) with lift of the trunk to the vertical (TLV) and maximum trunk lift (MTL), as well as using forward stand-and-reach test (FSR).

The majority of these tests (PL, AL and TL) assess flexibility by comparing each joint's range of motion with a reference chart. For each movement, the range of motion is scored using a scale from 0 to 4 points $(0=$ poor, $1=$ satisfactory, $2=$ good, $3=$ very good and $4=$ excellent). Since only whole numbers are used to score, for movements with a range of motion between two points of the assessment chart, the next lower value was registered. The remaining tests (RUL and FRS) are linear flexibility tests and the results are presented in centimetres $(\mathrm{cm})$.

In the LL flexibility tests (PL and AL in Table 1), the gymnasts performed the exercises with preferred (PLL) and non-preferred LL (NPLL). The PLL is the leg that gymnast prefers to perform the task and the NPLL is the support leg. For the analysis of LL flexibility tests, the results were grouped according with the origin of action (passive or active flexibility) and the preference of LL in performing the movement (PLL or NPLL), i.e., it was assigned two values for passive flexibility (one value for PLL and one value for NPLL). The mean values of tests PLF, PLS and PLB were then used in the analysis for passive flexibility. Likewise, for active flexibility (one value for PLL and one value for NPLL) the mean values of tests ALF, ALS and ALB were calculated and used for analysis. 
Table 2. Summary of Flexibility Tests

\begin{tabular}{|c|c|c|c|c|c|}
\hline Test & $\begin{array}{l}\text { Leg up with } \\
\text { help of the } \\
\text { hand (PL) }\end{array}$ & $\begin{array}{l}\text { Leg up without } \\
\text { help of the } \\
\text { hand (AL) }\end{array}$ & $\begin{array}{c}\text { Rotation of } \\
\text { the upper } \\
\text { limbs (RUL) }\end{array}$ & $\begin{array}{c}\text { Trunk Lift } \\
\text { (TL) }\end{array}$ & $\begin{array}{c}\text { Forward Stand- } \\
\text { and-Reach } \\
\text { (FSR) }\end{array}$ \\
\hline Purpose & $\begin{array}{l}\text { To evaluate the } \\
\text { passive } \\
\text { flexibility of the } \\
\text { hip joint }\end{array}$ & $\begin{array}{l}\text { To evaluate the } \\
\text { active flexibility } \\
\text { of the hip joint }\end{array}$ & $\begin{array}{c}\text { To evaluate } \\
\text { the active } \\
\text { flexibility of } \\
\text { the } \\
\text { scapulohumer } \\
\text { al joint }\end{array}$ & $\begin{array}{l}\text { To evaluate } \\
\text { the active } \\
\text { flexibility of } \\
\text { the spinal } \\
\text { joints }\end{array}$ & $\begin{array}{c}\text { To evaluate the } \\
\text { active flexibility } \\
\text { of the spinal and } \\
\text { hip joints }\end{array}$ \\
\hline Measure & $\begin{array}{c}\text { Maximum } \\
\text { amplitude angle } \\
\text { of the hip joint }\end{array}$ & $\begin{array}{c}\text { Maximum } \\
\text { amplitude angle } \\
\text { of the hip joint }\end{array}$ & $\begin{array}{l}\text { Minimum } \\
\text { distance of } \\
\text { hands during } \\
\text { the rotation of } \\
\text { upper limbs }\end{array}$ & $\begin{array}{l}\text { Amplitude } \\
\text { angle of the } \\
\text { spinal joints } \\
\text { in extension } \\
\text { movement } \\
\text { (according } \\
\text { to the } \\
\text { defined } \\
\text { limits: } 90^{\circ} \\
\text { or } \\
\text { maximum } \\
\text { amplitude) }\end{array}$ & $\begin{array}{c}\text { Maximum } \\
\text { distance of } \\
\text { fingers from the } \\
\text { edge of the bench }\end{array}$ \\
\hline Equipment & $\begin{array}{l}\text { Table } 5 \text { points } \\
\text { (chart for rating) }\end{array}$ & $\begin{array}{l}\text { Table } 5 \text { points } \\
\text { (chart for rating) }\end{array}$ & $\begin{array}{l}\text { Ruler with } \\
\text { scale (cm) }\end{array}$ & $\begin{array}{c}\text { Table } 5 \\
\text { points (chart } \\
\text { for rating) }\end{array}$ & Measuring tape \\
\hline Position & $\begin{array}{c}\text { Standing } \\
\text { straight (wall, } \\
\text { bar or backrest) }\end{array}$ & $\begin{array}{c}\text { Standing } \\
\text { straight (wall, } \\
\text { bar or backrest) }\end{array}$ & $\begin{array}{l}\text { Standing with } \\
\text { the ruler in } \\
\text { front of the } \\
\text { body with the } \\
\text { minimum } \\
\text { distance } \\
\text { between } \\
\text { hands }\end{array}$ & $\begin{array}{l}\text { Lying on the } \\
\text { stomach }\end{array}$ & $\begin{array}{l}\text { Standing on the } \\
\text { bench with knees } \\
\text { fully extended } \\
\text { and toes at the } \\
\text { edge of the bench }\end{array}$ \\
\hline Action & $\begin{array}{l}\text { Leg up forward } \\
\text { (PLF), sideways } \\
\text { (PLS) or } \\
\text { backward (PLB) } \\
\text { to maximum } \\
\text { with help of the } \\
\text { hand. Perform } \\
\text { with both legs }\end{array}$ & $\begin{array}{l}\text { Leg up forward } \\
\text { (ALF), sideways } \\
\text { (ALS) or } \\
\text { backward } \\
\text { (ALB) to } \\
\text { maximum } \\
\text { without help of } \\
\text { the hand. } \\
\text { Perform with } \\
\text { both legs } \\
\end{array}$ & $\begin{array}{l}\text { Rotation of } \\
\text { the extended } \\
\text { upper limbs } \\
\text { back without } \\
\text { trunk } \\
\text { inclination } \\
\text { (anteversion } \\
\text { and } \\
\text { retroversion) }\end{array}$ & $\begin{array}{l}\text { Lift trunk } \\
\text { upwards, } \\
\text { without help } \\
\text { until vertical } \\
\text { (TLV) or the } \\
\text { maximum } \\
\text { extent } \\
\text { (MTL) }\end{array}$ & $\begin{array}{l}\text { Leaning forward } \\
\text { and reach toward } \\
\text { the ground. } \\
\text { Repeat } 4 \text { times; } \\
\text { on the fourth trial, } \\
\text { hold the position } \\
\text { of maximum } \\
\text { reach for one } \\
\text { complete second }\end{array}$ \\
\hline
\end{tabular}

Source: Klentrou et al. 2010

${ }^{I}$ Test from Douda et al. 2008, ${ }^{2}$ Test adapted from Klentrou et al. 2010

Furthermore, in the LL flexibility tests, a limit of $15 \%$ bilateral difference was established as the maximum value for a normal difference (i.e. no asymmetry) between PLL and NPLL (Marchetti 2009). The asymmetry index (AI) was calculated using the equation (Chavett et al. 1997): AI $(\%)=[($ PLLNPLL)/PLL]*100, where AI represents the asymmetry index, PLL is the preferred lower limb test result (mean value achieved in the active and passive flexibility tests with PLL) and NPLL is the non-preferred lower limb test result (mean value achieved in the active and passive flexibility tests with NPLL). 
The flexibility tests were conducted in training environment following strictly the protocol proposed. Two cameras (Nikon D5300, Tokyo-Japan and Samsung VP DX 100, South Korea) were used to register the images and videos. The videos were then analyzed by two international judges in two different occasions 10 days apart. We observed high values of intra-examiner reliability (Kendall Coefficient of Concordance 0.83-0.97) and inter-examiner reliability (Intraclass Correlation Coefficient 0.84-0.97), which confirms a high quality of information.

Statistical Procedures: Statistical analysis was performed using the Statistical Package for Social Sciences (SPSS 23.0). The significance level was set at 5\%. Descriptive statistics were performed using the mean, standard deviation, median, minimum and maximum values. Kruskal-Wallis and Wilcoxon tests were used to compare flexibility scores across competition levels. Pearson correlation and linear regression were used to verify the variables that explain performance.

\section{Results}

Lower Limb flexibility tests: Table 3 shows that passive flexibility was higher than active flexibility with both PLL and NPLL in all groups $(p<0.001)$. Furthermore, there is a high inter-individual variability in the groups in both flexibility analysis and LL. According to the asymmetry index, we found higher asymmetries levels in active than passive flexibility.

When we compared LL flexibility between competition levels (Table 3), we found that all groups had significant differences $(p \leq 0.05)$ in all LL flexibility tests (passive and active). Thus, the higher the competition level, better the flexibility results with both PLL and NPLL.

Table 3. Mean, Standard Deviation and Range Values Achieved in the Flexibility Tests Performed with PLL and NPLL; Asymmetry Index by Competition Levels

\begin{tabular}{|l|c|c|c|c|c|c|}
\hline & $\begin{array}{c}\text { Competition } \\
\text { level }\end{array}$ & $\begin{array}{c}\text { PLL } \\
\mathbf{( x \pm s d )}\end{array}$ & $\begin{array}{c}\text { NPLL } \\
(\mathbf{x} \pm \mathbf{s d})\end{array}$ & $\begin{array}{c}\text { PLL } \\
\text { Range } \\
(\mathbf{p t s})\end{array}$ & $\begin{array}{c}\text { NPLL } \\
\text { Range } \\
(\mathbf{p t s})\end{array}$ & AI (\%) \\
\hline \multirow{3}{*}{$\begin{array}{l}\text { Passive } \\
\text { Flexibility*1,2,3 }\end{array}$} & Base & $2.1 \pm 0.8$ & $1.5 \pm 0.6$ & $0.3-4.0$ & $0.3-3.3$ & $28.6 \%$ \\
\cline { 2 - 7 } & $\mathbf{1}^{\text {st }}$ division & $3.2 \pm 0.6$ & $2.4 \pm 0.7$ & $0.7-4.0$ & $0.7-4.0$ & $25.0 \%$ \\
\cline { 2 - 7 } & Elite & $3.7 \pm 0.5$ & $3.3 \pm 0.6$ & $2.7-4.0$ & $2.3-4.0$ & $10.8 \%$ \\
\hline \multirow{3}{*}{$\begin{array}{l}\text { Active } \\
\text { Flexibility*1,2,3 groups }\end{array}$} & $2.6 \pm 0.9$ & $2.0 \pm 0.9$ & $0.3-4.0$ & $0.3-4.0$ & $23.0 \%$ \\
\cline { 2 - 7 } & Base & $1.4 \pm 0.8$ & $0.9 \pm 0.7$ & $0-3.0$ & $0-2.7$ & $35.7 \%$ \\
\cline { 2 - 7 } & $\mathbf{1}^{\text {st division }}$ & $2.4 \pm 0.6$ & $1.7 \pm 0.7$ & $0-3.7$ & $0-3.3$ & $29.2 \%$ \\
\cline { 2 - 7 } & Elite & $2.9 \pm 0.6$ & $2.4 \pm 0.6$ & $2.0-3.7$ & $1.3-3.3$ & $17.2 \%$ \\
\hline
\end{tabular}

Legend - PLL: preferred lower limb; NPLL: non-preferred lower limb; pts: points; AI: asymmetry index; $*^{l}: p \leq 0.05$ - significant differences between all groups (base vs. ${ }^{\text {st }}$ division; base vs. elite; $1^{\text {st }}$ division vs. elite); *2: $p \leq 0.05$ - significant differences between lower limbs (PLL vs. NPLL); *3: $p \leq 0.05$ - significant differences in passive versus active flexibility with preferred and non-preferred lower limb in all competition levels.

Furthermore, significant differences were found in PLL versus NPLL in all groups in both passive $(p<0.001)$ and active $(p<0.001)$ flexibility tests. According 
to asymmetry index (Table 3), the higher the competition level, lower the functional asymmetries levels between LL. Figure 1 presents the flexibility asymmetry index by competition level. According to the recommended limit of $15 \%$ (Marchetti 2009) bilateral difference between PLL and NPLL, we observed high asymmetries levels in flexibility: overall, $69.4 \%$ and $71.4 \%$ of gymnasts in this study presenting different functional asymmetry levels in passive and active flexibility, respectively.

Figure 1. Individual Analysis of Flexibility Level by Competition Levels according to the Classes of Asymmetry Index.

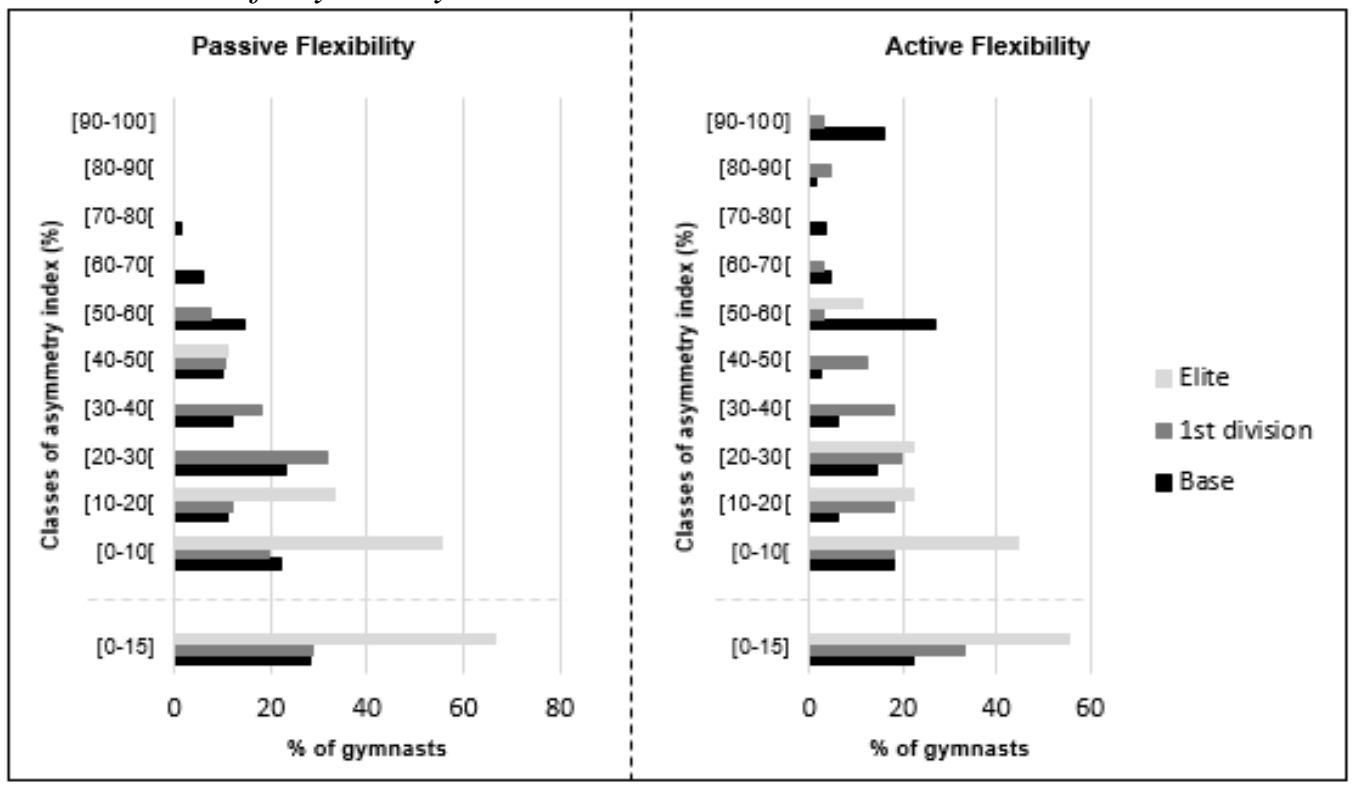

Gymnasts in the Elite group had lower asymmetry and the majority of this group did not present the referred functional asymmetry. On the other hand, the $1^{\text {st }}$ division and Base showed functional asymmetries of different and higher magnitude.

Upper limbs and multi-joint testing: The gymnasts presented the same performance for shoulder turn in anteversion and retroversion, therefore, only one value was presented in the results of RUL test. In the UL and multi-joint flexibility tests (Table 4), the higher the competition level, higher the flexibility in all tests performed. However, significant differences were found in all tests between the Base group and the other two groups, i.e., $1^{\text {st }}$ division and Elite. No significant differences were found between $1^{\text {st }}$ division and Elite: RUL $(p=0.393)$; FSR $(\mathrm{p}=0.195) ; \operatorname{TLV}(\mathrm{p}=0.349) ; \operatorname{MTL}(\mathrm{p}=0.468)$. 
Table 4. Upper Limbs and Multi-Joint Flexibility Tests by Competition Levels. Range Values, CV Percentage, Mean, Standard Deviation and P Values

\begin{tabular}{|c|c|c|c|c|c|c|c|c|c|c|}
\hline & \multicolumn{3}{|c|}{ Base $(n=82)$} & \multicolumn{3}{|c|}{$1^{\text {st }}$ Division $(\mathrm{n}=66)$} & \multicolumn{3}{|c|}{ Elite $(n=9)$} & \multirow{2}{*}{$\begin{array}{l}\text { Proof } \\
\text { Value }\end{array}$} \\
\hline Tests & Range & $\mathrm{CV}(\%)$ & $\mathrm{x} \pm \mathrm{sd}$ & Range & $\mathrm{CV}(\%)$ & $\mathrm{x} \pm \mathrm{sd}$ & Range & $\mathrm{CV}(\%)$ & $\mathrm{x} \pm \mathrm{sd}$ & \\
\hline $\begin{array}{l}\text { RUL } \\
(\mathbf{c m})\end{array}$ & $0-62.0$ & $63.1 \%$ & $24.9^{1,2} \pm 15.7$ & $0-61.0$ & $106.7 \%$ & $15.0^{1} \pm 16.0$ & $0-38.0$ & $147.6 \%$ & $8.2^{2} \pm 12.1$ & 0.000 \\
\hline $\begin{array}{l}\text { FSR } \\
(\mathrm{cm})\end{array}$ & $0-38.5$ & $40.4 \%$ & $18.3^{1,2} \pm 7.4$ & $-13.0-34.8$ & $35.5 \%$ & $21.7^{1} \pm 7.7$ & $21.7-28.2$ & $8 \%$ & $24.7^{2} \pm 2.0$ & 0.001 \\
\hline $\begin{array}{l}\text { TLV } \\
\text { (pts) }\end{array}$ & $0-4.0$ & $51.9 \%$ & $2.7^{1,2} \pm 1.4$ & $1.0-4.0$ & $15.8 \%$ & $3.8^{1} \pm 0.6$ & $4.0-4.0$ & $0 \%$ & $4.0^{2} \pm 0.0$ & 0.000 \\
\hline $\begin{array}{l}\text { MTL } \\
\text { (pts) }\end{array}$ & $0-4.0$ & $76.5 \%$ & $1.7^{1,2} \pm 1.3$ & $0-4.0$ & $31.3 \%$ & $3.2^{1} \pm 1.0$ & $2.0-4.0$ & $19.4 \%$ & $3.6^{2} \pm 0.7$ & 0.000 \\
\hline
\end{tabular}

Legend-RUL: rotation of the upper limbs; FSR: forward stand-and-reach; TLV: trunk lift vertical; MTL: maximum trunk lift; pts: points; ${ }^{*} \leq 0.05:$ significant differences - ${ }^{\prime}$ : Base versus $1^{\text {st }}$ division; ${ }^{2}$ : Base versus Elite. CV: coefficient of variation. 
Furthermore, the range and standard deviation values (Table 4) evidence the high dispersion of results especially in Base and $1^{\text {st }}$ division groups. The coefficient of variation (\%) calculated using mean and standard deviation shows that the higher the competition level, lower the inter-individual variability, except in the RUL test, where the Elite group presented a higher dispersion around the mean.

In TLV, $69.4 \%$ of gymnasts reached an excellent level (4) and in MTL only $35 \%$ of gymnasts obtained the same flexibility level. This difference is more evident when we analyzed the results by competition level. As expected, excellent level was achieved by $48.8 \%$ (TLV) and $13.4 \%$ (MTL) of gymnasts from Base; $90.9 \%(\mathrm{TLV})$ and $57.6 \%$ (MTL) of gymnasts from $1^{\text {st }}$ division; $100 \%$ (TLV) and $66.7 \%$ (MTL) of Elite gymnasts. Thus, significant differences were found in TLV versus MTL in Base $(\mathrm{p}<0.001)$ and $1^{\text {st }}$ division $(\mathrm{p}<0.001)$.

Flexibility Profile: Figure 2 shows the flexibility profiles by competitive level. We confirmed a clear advantage of the Elite group in all flexibility tests. As expected, $1^{\text {st }}$ division presented intermediate results, with higher values than Base and lower than Elite. This group also showed a lower variability in the results. The Base obtained the lower results in all flexibility tests and with below average values.

Figure 2. Flexibility Profile by Competitive Level

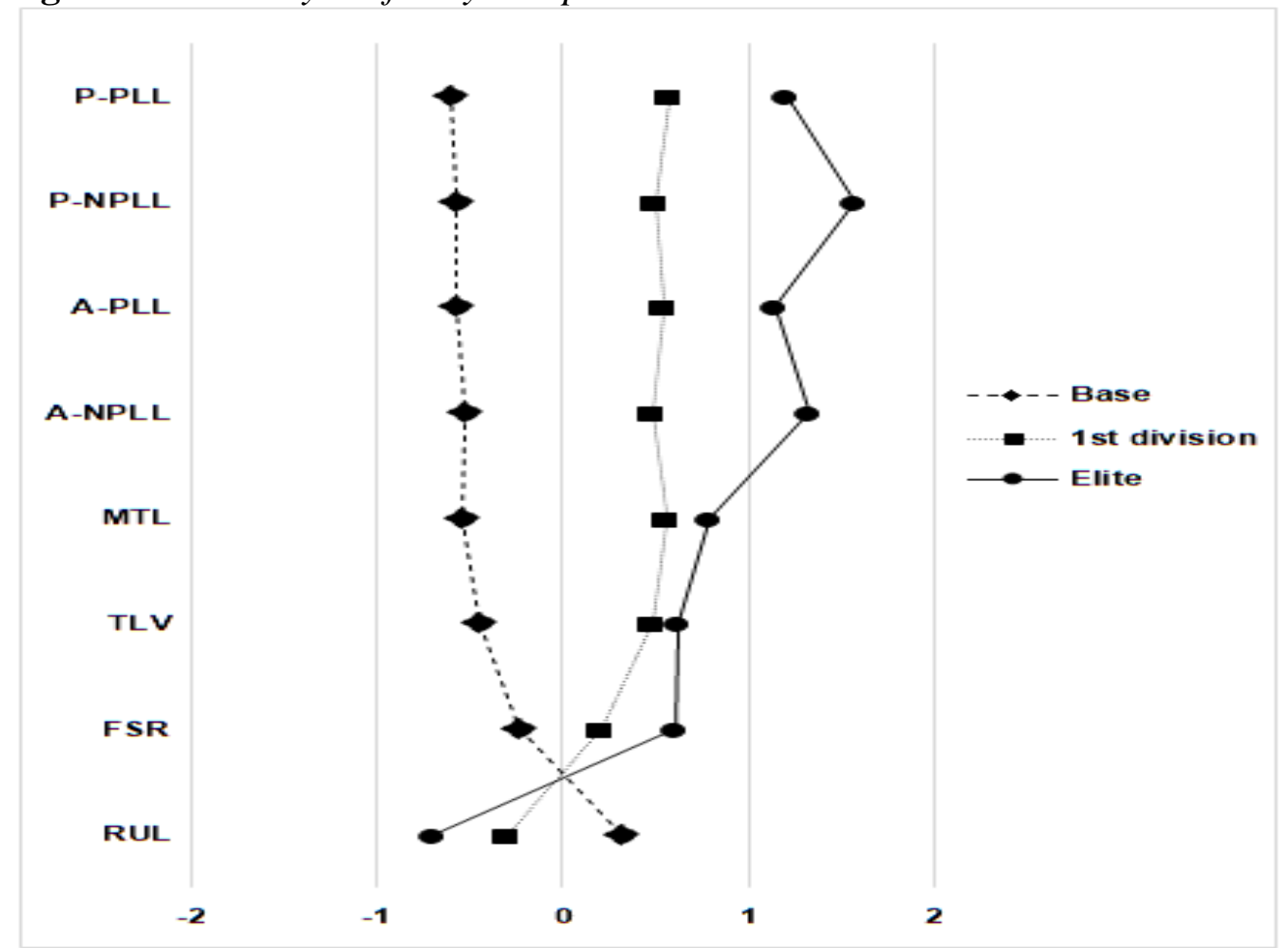

Legend - P-PLL: Passive flexibility with preferred lower limb; P-NPLL: Passive flexibility with nonpreferred lower limb; A-PLL: Active flexibility with preferred lower limb; A-NPLL: Active flexibility with non-preferred lower limb; MTL: Maximum Trunk Lift; TLV: Trunk Lift Vertical; FSR: Forward Stand-and-Reach; RUL: Rotation of the upper limbs. 
The analysis of RUL test is different from the other flexibility tests (Figure 2). The results in this test showed the same progression: Base with lower results, followed by $1^{\text {st }}$ division and Elite with the best results.

Analyzing all flexibility variables and the competitive performance of gymnasts, the RUL, TLV and MTL, as well as the LL scores (passive PLL/NPLL and active PLL/NPLL) were significantly correlated with performance scores (Figure 3). Thus, the higher the flexibility in the LL tests, as well as in TLV and MTL tests, the higher the score in competition while the lower the values achieved in RUL test, higher the score in competition.

Figure 3. Flexibility Variables with Significant Correlation with Final Performance Score across Competition Levels

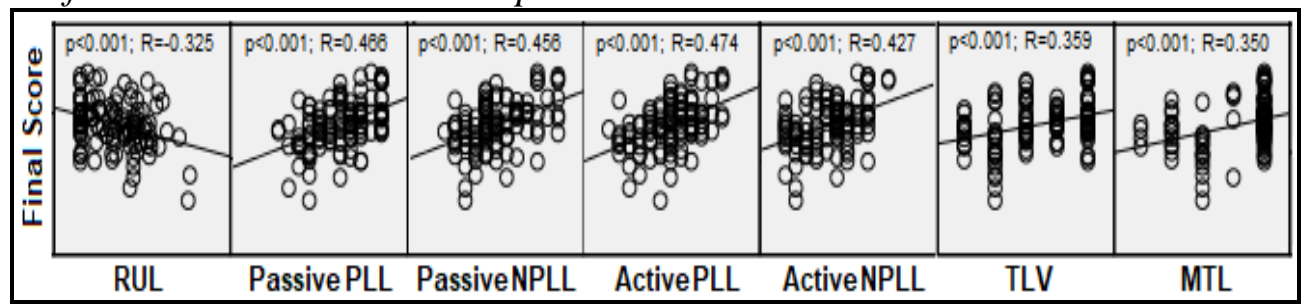

Legend - RUL: Rotation of the upper limbs; PLL: Preferred lower limb; NPLL: Non-preferred lower limb; TLV: Trunk Lift Vertical; MTL: Maximum Trunk Lift.

However, only the active flexibility tests with PLL (active PLL) presented statistical significance in the model of linear regression $(\mathrm{p}<0.001 ; \mathrm{F}=31.623)$. According to $\mathrm{R}^{2}$ adjusted, this variable explained $21.8 \%$ of variance of performance. The regression equation was: Performance Score $=45.919+$ 4.884*Active PLL; therefore, the higher the active flexibility with PLL, the higher the score in competition. On the other hand, analyzing the groups by competition level, significant correlations of moderate intensity were found between the performance score and different flexibility variables: Base (Active PLL; Passive PLL and TLV); $1^{\text {st }}$ division (all variables, except the FRS test); and Elite (Active PLL). Thus, there is no common pattern in the results of linear regression across competition levels. Specifically, only Active PLL explained part of the performance in the Base $\left(\mathrm{p}=0.001 ; \mathrm{F}=11.526 ; \mathrm{R}^{2}\right.$ adjusted $=0.145 ; \mathrm{y}=46.958+4.531^{*}$ Active PLL) and Elite $\left(\mathrm{p}=0.032 ; \mathrm{F}=7.129 ; \mathrm{R}^{2}\right.$ adjusted $=0.434 ; \mathrm{y}=51.306+5.938^{*}$ Active PLL) groups while for $1^{\text {st }}$ division the predicting variables were Passive PLL and RUL $\left(\mathrm{p}=0.001 ; \mathrm{F}=8.958 ; \quad \mathrm{R}^{2}\right.$ adjusted $=0.295 ; \mathrm{y}=38.412+5.850 *$ Passive PLL $0.168 *$ RUL).

\section{Discussion}

The participants of this study were competitive RG gymnasts from three competitive levels in Portugal (Base, $1^{\text {st }}$ division and Elite). The gymnasts competing in the Base and $1^{\text {st }}$ division levels are selected by their coaches. Portugal Gymnastics Federation selects the Elite gymnasts through predefined criteria in the 
junior and senior categories. These gymnasts join the individual Portugal National RG Team. To stay in the Elite group at the end of each sports season, the gymnast must keep scores previously defined and sufficient for to be considered able to represent Portugal in international competitions. As expected, the number of training hours per week are different between the Elite (31.2 \pm 6.2 hours per week) and the other groups $\left(13.9 \pm 6.4\right.$ and $18.5 \pm 6.4$ hour per week for Base and $1^{\text {st }}$ division respectively). According to Ávila-Carvalho et al. (2013), in order to achieve the necessary preparation for a good performance in RG, elite gymnasts train 25-30 hours per week and in some cases, 40 hours per week. The Elite gymnasts also had more years of practice in RG. We observed that the higher the competition level, higher number of years of practice: $8.2 \pm 1.9$ years (Elite), $6.6 \pm 2.6$ years $\left(1^{\text {st }}\right.$ division) and 5.6 \pm 3.2 years (Base). In addition, the higher the competition level, lower the age of training onset: $6.0 \pm 1.5$ years (Elite), $6.4 \pm 1.9$ years $\left(1^{\text {st }}\right.$ division) and 7.2 \pm 2.6 years (Base). The age of training onset in elite gymnasts is in accordance with indications by several authors (Georgopoulos et al. 2012, Law et al. 2007 Poliszczuk and Brod 2010), who suggest that the RG training begins at the early age of 5-6 years and continues throughout childhood and adolescence. Thus, the training onset, training years and training volume are related to deliberate practice and the necessity of athletes to have a minimum time of experience in order to be successful in the sport (Ericsson et al. 1993). In this sense, to make a National Team demands a hard work and effort over many years.

Therefore, to achieve great performances in RG, the daily work should be detailed, planned, organized and multilateral towards the harmonious development of the gymnasts' body, and the adaptations of their body to the requirements of this sport (Laffranchi 2001). Indeed, the multilateral and harmonious development is very important in the flexibility work (Lisitskaya 1995). The flexibility assumes a determinant role in RG performance because high ranges of motion are required in this sport (Sands et al. 2016). Furthermore, the flexibility is essential also in the execution of most body difficulty elements present in the RG Code of Points (Douda et al. 2008, Fernandez-Villarino and Sierra-Palmeiro 2013).

In RG, the gymnasts should have flexible joints, especially in the hip, shoulders and spine (Jastrjembskaia and Titov 1999, Stadnik et al. 2010, Volpi da Silva et al. 2008). Thus, the maximum passive and active flexibility was measured in our study in specific RG movements using these main joints. According to McGuigan (2014), the choice of tests should be specific to the sport, because general tests do not always correlate well with athletes' competitive performance. Therefore, we use tests recommended by FIG. The LL flexibility tests were performed on the bar and are composed by exercises daily used in the training sessions (Laffranchi 2001, Lebre and Araujo 2006). This justifies the familiarity demonstrated by gymnasts in most tests. According to (Laffranchi 2001), the exercises on the bar have as objective the development of the physical capacities and the assimilation of the basic positions of the RG to a correct and conscious postural attitude, facilitating, outside the bar, the execution of the movements. In the LL flexibility tests, we observed higher values in passive flexibility than active 
flexibility in all groups. However, these results were expected since the passive flexibility is typically higher than active flexibility (Weineck 2003).

Similar flexibility tests were performed by Batista-Santos et al. (2015b) in a longitudinal study with elite Portuguese gymnasts. The authors confirmed high homogeneity in the results achieved by gymnasts with both PLL and NPLL with a range of 3 to 4 points. On the other hand, Batista-Santos et al. (2015a) used the same tests in a study with gymnasts from different competition levels and found a high inter-individual variability in the results. Furthermore, the authors observed that $86.7 \%$ of gymnasts presented high indexes of flexibility asymmetry between the PLL and NPLL. In a study conducted by Douda et al. (2008) the following flexibility tests were used in elite and non-elite gymnasts: side splits with right and left leg forward, where the tester measured the distance of the middle of the inferior side of the lateral malleolus from the floor in centimeters; and leg-lift tests forward and sideward with the right and left leg, where a goniometer was used to determine the maximum amplitude in degrees. The authors confirmed higher flexibility values in elite gymnasts, although these gymnasts showed on average higher differences between the right and left legs in all tests. However, this point was not analyzed by the authors in the study.

Although, RG aims to exercise the entire body bilaterally, in order to achieve high performance, repetitive motor actions only with the preferred side are repetitively performed in training, which eventually characterizes a unilateral practice (Teixeira and Paroli 2000, Zaidi 2011) and may still cause muscle imbalances (Lisitskaya 1995). Thus, the analysis of LL flexibility in RG promotes a very important discussion about the functional motor asymmetries. Indeed, when we compared the flexibility between LL, we observed that in general, $69.4 \%$ and $71.4 \%$ of the gymnasts in this study presented different functional asymmetries in passive and active flexibility, respectively, according to a limit of $15 \%$ bilateral difference between PLL and NPLL proposed by (Marchetti 2009). Furthermore, we found functional asymmetries of different magnitude among groups. However, higher the competition level, the lower the functional asymmetry.

Although the mean value of asymmetry index in passive flexibility in elite gymnasts $(10.8 \%)$ was lower than the proposed limit (15\%), significant differences were observed in PLL and NPLL probably because $33.3 \%$ of gymnasts presented asymmetry index between $16.7 \%$ and $41.7 \%$.

Thus, the functional asymmetry is mainly the result of long-term RG training and generally the consequence of wrong work, which is identified later making its correction more complex (Lisitskaya 1995). Thus, the persistent asymmetric load, through the support mechanism in one leg, which is often used in the RG training, is one of the factors that make gymnasts more prone to scoliosis (Volpi da Silva et al. 2008). Lisitskaya (1995) suggests that when these differences exceed normal limits, they may cause imbalances in the physical development of gymnasts and in some cases can cause stretches of 2 or $3 \mathrm{~cm}$ of the LL most used, pelvic torsion or lumbar scoliosis. 
The motor experience may either strengthen the preference for a particular body side or decrease the intensity of this preference to equalize the two sides, when the LL are appropriately stimulated (Zaidi 2011). Some studies (Andrade 2012, Cobalchini and Silva 2008, Teixeira 2001, Teixeira et al. 2003) support the idea that improving and increasing the use of NPLL through specific and targeted training processes to this effect it promotes a reduction of the functional asymmetries. In this sense, Teixeira (2001) carried out a study to verify if functional asymmetries established during the long-term practice of motor skills in soccer could be modified as an effect of increased training with the NPLL. The author found that the differences were reduced with more targeted training for player necessities, showing the high potential of the emphasis in the practice on the NPLL to modify functional asymmetries in the performance. In Martins et al. (2009) study, the authors evaluate the amplitude of the hip flexion movement of 52 Brazilian gymnasts, and observed that the gymnasts presented higher flexibility level with PLL than NPLL. If we analyze the flexibility levels without considering functional asymmetry, we are promoting a strengthening of unilateral practice in RG. Therefore, the functional asymmetry evaluation is extremely important in this sport, once that it allows the analysis of the harmonious development of the gymnast's body (Batista-Santos et al. 2015a). Furthermore, the evident asymmetries can reflect negatively in the physical and technical preparation of the gymnasts and, in many cases, can cause changes in the posture (Lisitskaya 1995). Thus, to avoid the gradual development of functional asymmetries in RG, it is necessary to highlight the importance of bilateral work. The coaches have a fundamental role in the correct physical preparation of the gymnasts. In addition, they have the responsibility to motivate the gymnasts to work both LL with the same intensity in order to avoid the overload of one body side and decompensations that in the longterm can induce injuries and or high asymmetries levels (Batista-Santos et al. 2015a).

Frutuoso et al. (2016) studied the influence of lateral preference of the lower extremity on anthropometric, range of motion, and isokinetic torque measurements of RG athletes. The bilateral torque asymmetry was accepted as being normal up to a $10 \%$ level. The authors observed the preferred limb showed larger thigh girth and anatomical cross-sectional area, higher ankle dorsiflexor range of motion and higher torque production in some muscles (hip flexor at $60^{\circ} \cdot \mathrm{s}-$ 1 and plantarflexor at $180^{\circ} \cdot \mathrm{s}-1$ ) compared to the non-preferred limb. Thus, the authors considered that the bilateral differences seem to be strictly related to lateral preference and $\mathrm{RG}$ training.

Sometimes the shoulders flexibility training is neglected during RG training due to lack of time or even by other priorities of coaches (Santos 2011), although this joint is very important in RG (Palmer 2003). In our study, the higher the competitive level, better the results in the RUL test. Indeed, the higher the competitive level, the higher the training volume and, probably, the greater time dedicated to the training of physical capacities. The shoulder flexibility test used in our study was also used by several authors (Douda et al. 2008, Radaš and Bobić 2011, Román et al. 2012). These studies presented different types of samples: 
Douda et al. (2008) evaluated the shoulders flexibility in elite $(16.0 \pm 11.5 \mathrm{~cm})$ and non-elite $(17.3 \pm 12.7 \mathrm{~cm})$ gymnasts, Radaš and Bobić (2011) evaluated gymnasts $(38.6 \pm 11.5 \mathrm{~cm})$ and non-gymnasts $(75.9 \pm 19.1 \mathrm{~cm})$, Román et al. (2012) evaluated artistic $(58.5 \pm 12.3 \mathrm{~cm})$ and rhythmic gymnasts $(24.0 \pm 22.4 \mathrm{~cm})$. We observed that no result was higher than the Portuguese gymnasts from $1^{\text {st }}$ division $(15.0 \pm 16.0 \mathrm{~cm})$ and Elite $(8.2 \pm 12.1 \mathrm{~cm})$. Furthermore, the results with high standard deviation values show that this test generally present a high inter-individual variability.

The other multi-joint test used in our study was the FRS test (forward standand-reach). We confirmed that the higher the competitive level, the higher the values achieved by gymnasts in this test. No studies were found with this test included in the flexibility evaluation. However, the sit-and-reach test (SAR) was used as a flexibility test for rhythmic gymnasts in some studies (Douda et al. 2008, Miletić et al. 2004, Miletić et al. 2004). The values reached in the SAR test are naturally higher than in the FRS test, once that the FRS test use the level of the feet as zero mark, while the SAR test usually have the zero mark before the feet. Therefore, the results of these different tests cannot be directly compared.

The RG also demands a high level of spinal flexibility, particularly flexibility of the lumbar spine, since the gymnasts present in their competition routines many movements and elements that require a great amplitude of spine joints (Santos 2011). Therefore, this capacity is trained intensively from very young ages (Sands et al. 2016).

Boligon et al. (2015) performed a study to evaluate the relation between flexibility and execution/validation of five elements of RG present in the RG-CoP (FIG 2012). Among the flexibility movements used in the analysis, the gymnasts performed the trunk hyperextension (the gymnast stood in lying prone, with the legs closed, overstretched the trunk with the arms outstretched, and held this position for five seconds without assistance). High correlations $(r=-0.76)$ were found between the score of technical elements and trunk flexibility. The negative sign of the correlation means that the higher the score, the lower the trunk angle, which means a higher range of motion. These authors concluded that the trunk flexibility has a great importance in perfectly executing the technical elements evaluated, and suggested that it is also important for other flexibility elements that use this multijoint body segment.

The test proposed by FIG to assess the level of spine flexibility corresponds to a body difficulty element included in the current Code of Points (FIG 2016), but are not usually used in the competition routines because of its low value. However, this movement is widely used in RG training for the work of flexibility and strength, performed through of exercises with repetitions and or position maintenance. Although it is a test with the objective of evaluating the flexibility level of the spinal joints, strength is also important in the execution of this movement. Thus, we felt the need to include another test with the same movement, but with a higher amplitude degree, in which we could get a greater discriminatory power between gymnasts of our study. Therefore, we applied the TLV test with trunk lift until to the vertical as well as the MTL test with maximum trunk lift. As expected, many 
gymnasts reached level 4 in the TLV test and obtained lower results in the MTL test as the extension movement of the spine to the maximum amplitude necessitates a high level of spine flexibility. The TLV test implies flexibility and strength for position maintenance and we verified that there were gymnasts with limited flexibility levels in the spine joints that have been able to achieve the excellent result (level 4) in this test, probably due to the sufficient combination of flexibility and strength. On the other hand, many gymnasts with high spine flexibility failed to achieve the higher level in the MTL test. This result is probably due to the gymnasts showing high flexibility in spine joints, but not yet presenting sufficient strength to maintain the determined position.

Del Vecchio et al. (2014) evaluated the spine flexibility with the same movement of maximum spinal extension used in our study (in MTL test) but with hands behind the head and in degrees. The authors observed that the higher the age category, better the results in this test: young 115.2 \pm 26.2 degrees, junior 101.2 \pm 16.6 degrees; and senior $93.8 \pm 29.3$ degrees.

The spinal extension movement with the extended arms or with hands behind the head have different difficulty levels. This movement performed with the extended arms as is defined in the test of spine flexibility used in our study, increase the intensity muscular contraction in the exercise. Since it departs the weight of the UL of the spine and the hip, i.e., it departs the weight of the centre of mass, and the higher the distance, the higher the difficulty of performing the exercise (Campos 2000).

Kritikou et al. (2017) developed a study to examine the association between artistry score, physical abilities and anthropometric characteristics in 46 national level competitive rhythmic gymnasts (aged $9.9 \pm 1.3$ years). Among the physical tests, the authors used tests to main joints: hip (straight leg raise and sideways leg extension in degrees), spine (spinal flexibility ratio in percentage) and shoulders (shoulder flexion in degrees). These variables presented a significantly negative correlation with artistry score and or to its separate sub-components, expression, music and movement (in deduction points). Thus, the authors verified that the higher the flexibility level, lower the artistry penalization, showing the importance of flexibility in these joints. Furthermore, the sideways leg extension was the variable that demonstrated the higher contribution to the variance of the artistry score and its sub-components unity and music and movement.

Finally, all flexibility variables used in our study (except the FRS test) were significantly correlated with the score in competition. However, only the active flexibility tests with PLL (variable Active PLL) presented statistical significance in the model of linear regression and explained $21.8 \%$ of variance of performance. This result shows the essential importance of active flexibility in RG, once that the flexibility and strength in this sport must have a closely connected work and are considered essential to achieve a high-level performance (Cantó et al. 2009, Di Cagno et al. 2008).

Analyzing the groups by competition level, we found different variables explaining the variance in performance in each competition level: Active PLL in Base (14.5\%) and Elite (43.4\%); Passive PLL and RUL in $1^{\text {st }}$ division $(29.5 \%)$. 
Therefore, in addition to the active flexibility of LL, the passive flexibility of LL and shoulders flexibility are essential for success in RG. Indeed, it is important to note that all variables (except the FRS test) presented statistical significance in the simple regression model, demonstrating the high relevance of all flexibility tests performed in our study. However, probably due to the collinearity observed in some variables, not all of them were significant in the multi-linear regression model. The FRS test was not "sensitive" to the analysis of the competitive results, according to the non-significance presented, probably because the rhythmic gymnasts have already acquired a high level of hamstrings and lower back flexibility (Kritikou et al. 2017).

\section{Conclusions}

In the upper limbs, lower limbs and multi-joint flexibility tests, we observed that the higher the competition level, better the flexibility results, although significant differences were not found between $1^{\text {st }}$ division and Elite groups in upper limb and multi-joint flexibility tests. In the lower limb flexibility tests, all groups showed differences in passive and active flexibility between preferred and non-preferred lower limb. In addition, the higher the competition level, lower the asymmetry level. Only $30.6 \%$ of gymnasts in passive flexibility $(28.1 \%$ in Base; $28.8 \%$ in $1^{\text {st }}$ division and $66.7 \%$ in Elite) and $28.7 \%$ of gymnasts in active flexibility $\left(22.0 \%\right.$ in Base; $33.3 \%$ in $1^{\text {st }}$ division and $55.6 \%$ in Elite) presented bilateral differences according to the limits considered normal. Therefore, $69.4 \%$ and $71.4 \%$ of gymnasts in this study had functional asymmetry of different magnitude in passive and active flexibility, respectively. Finally, we observed that among the variables analyzed in the study, the active flexibility with preferred lower limb explained $21.8 \%$ of variance of success in competition. Analyzing the groups by competition levels, different variables explained the success in competition: active flexibility with preferred lower limb in Base and Elite; passive flexibility with preferred lower limb and rotation of the upper limbs in $1^{\text {st }}$ division.

\section{Acknowledgments}

The authors would like to thank the Portuguese Federation of Gymnastics, the gymnasts and coaches that permitted the making of this study possible.

\section{References}

Andrade J (2012) Efeito do treino do membro não preferido no desempenho motor e na assimetria motora funcional de jovens futebolistas. [Effect of non-preferred limb training on motor performance and functional motor asymmetry of young soccer players]. (Master), University of Porto, Porto. 
Ávila-Carvalho L, Klentrou P, Palomero ML, Lebre E (2013) Anthropometric profiles and age at menarche in elite group rhythmic gymnasts according to their chronological age. Science \& Sports 28(4): 172-180.

Batista-Santos A, Bobo-Arce M, Lebre E, Ávila-Carvalho L (2015a) Flexibilidad en gimnasia rítmica: asimetría funcional en gimnastas júnior portuguesas. [Flexibility in rhythmic gymnastics: functional asymmetry in Portuguese junior gymnasts]. Apunts. Educación Física y Deportes. 2(120): 19-26.

Batista-Santos A, Lemos ME, Lebre E, Ávila-Carvalho L (2015b) Active and passive lower limb flexibility in high level rhythmic gymnastics. Science of Gymnastics Journal 7( 2): 55-66.

Bobo-Arce M, Méndez-Rial B (2013) Determinants of competitive performance in rhythmic gymnastics. A review. Journal of Human Sport \& Exercise 8(3): 711- 717.

Boligon L, Deprá PP, Rinaldi I (2015) Influence of flexibility in the execution of movements in rhythmic gymnastics. Acta Scientiarum. Health Sciences 37(2): 141145.

Bordalo M, Portal M, Cader S, Perrotta N, Neto J, Dantas E (2015) Comparison of the effect of two sports training methods on the flexibility of rhythmic gymnasts at different levels of biological maturation. The Journal of Sports Medicine and Physical Fitness. 55(5): 457-463.

Campos MA (2000) Biomecânica da Musculação, Vol. 1. Rio de Janeiro: Sprint.

Cantó E, Sánchez A, Sánchez J (2009) Test más apropiados para la valoración funcional del deportista en gimnasia rítmica. [Most appropriate test for the valuation functional of the athlete in rhythmic gymnastics]. Efdeportes Revista Digital 13. Available at $\mathrm{http} / / / \mathrm{www}$.efdeportes.com/efd129/valoracion-funcional-del-deportista-en-gimnasiaritmica.htm.

Chavett P, Lafortune M, Gray J (1997) Asymmetry of lower extremity responses to external impact loading. Human Movement Science 16(4): 391-406.

Cobalchini R, Silva ER (2008) Treinabilidade do membro inferior não-dominante em atletas infantis de futebol. [Training of the non-dominant lower limb in children's soccer athletes]. EFDeportes, 13. Available at http://www.efdeportes. com/efd125 /treinabilidade-do-membro-inferior-nao-dominante-em-atletas-infantis-de-fute bol.htm.

Del Vecchio FB, Primeira M, Silva HC, Dall'Agnol C, Galliano LM (2014) Nível de aptidão física de atletas de ginástica rítmica: Comparações entre categorias etárias. [Physical fitness level of rhythmic gymnastics athletes: Comparisons between age categories]. Revista Brasileira de Ciência e Movimento. 22( 3): 5-13.

Di Cagno A, Baldari C, Battaglia C, Guidetti L, Piazza M (2008) Anthropometric characteristics evolution in elite rhythmic gymnasts. Italian Journal of Anatomy and Embryology 113(1): 29-36.

Di Cagno A, Baldari C, Battaglia C, Monteiro MD, Pappalardo A, Piazza M, Guidetti L (2009) Factors influencing performance of competitive and amateur rhythmic gymnastics - Gender differences. Journal of Science and Medicine in Sport 12(3): 411-416.

Douda H, Toubekis A, Avloniti A, Tokmakidis S (2008) Physiological and anthropometric determinants of rhythmic gymnastics performance. International Journal of Sports Physiology And Performance 3(1): 41-54.

Ericsson KA, Krampe RT, Tesch-Römer C (1993) The Role of deliberate practice in the acquisition of expert performance. Psychological Review 100(3): 363-406. 
Fernandez-Villarino MMB-A, Sierra-Palmeiro E (2013) Practical Skills of Rhythmic Gymnastics Judges. Journal of Human Kinetics 39: 243-249.

FIG (2012) Code of Points for Rhythmic Gymnastics: 2013-2016. Available at http://www.fig-gymnastics.com/site/page/view?id=472

FIG (2016) Code of Points for Rhythmic Gymnastics: 2016-2020. Available at http://www.fig-gymnastics.com/site/rules/rules.php.

Frutuoso A, Diefenthaeler F, Vaz M, Freitas C (2016) Lower limb asymmetries in Rhythmic Gymnastics athletes. The International Journal of Sports Physical Therapy 11(1): 34-43.

Georgopoulos N, Theodoropoulou A, Roupas N, Rottstein L, Tsekouras A, Mylonas P, Vagenakis GA, Koukkou E, Armeni AK, Sakellaropoulos G, Leglise M, Vagenakis AG, Markou K (2012) Growth velocity and final height in elite female rhythmic and artistic gymnasts. Hormones 11(1): 61-69.

Jastrjembskaia N, Titov Y (1999) Rhythmic Gymnastics - Hoop, Ball, Clubs, Ribbon, Rope. EUA: Human Kinectics Champaign.

Klentrou N, Gorbulina N, Aleksandrova N, Delle-Chiae D, Ferrand C, Fink H (2010) Age Group Development Program for Rhythmic Gymnastics: Sample Physical Testing Program. Lausanne, Switzerland: International Gymnastics Federation.

Kritikou M, Donti D, Bogdanis G, Donti A, Theodorakou K (2017) Correlates of artistry performance scores in preadolescent rhythmic gymnasts. Science of Gymnastics Journal 9(2): 165-177.

Laffranchi B (2001) Treinamento Desportivo Aplicado à Ginástica Rítmica. [Sports Training Applied to Rhythmic Gymnastics]. Londrina, Paraná: UNOPAR.

Law MP, Côté J, Ericsson KA (2007) Characteristics of expert development in rhythmic gymnastics: A retrospective study. Journal International Journal of Sport and Exercise Psychology 5(1): 82-103.

Lebre E, Araujo C (2006) Manual de Ginástica Rítmica. [Manual of Rhythmic Gymnastics]. Porto: Porto Editora.

Lisitskaya T (1995) Gimnasia Rítmica. [Rhythmic Gymnastics]. Deporte \& Entrenamiento. Barcelona: Editorial Paidotribo.

Marchetti PH (2009) Investigações sobre o controle motor e postural nas assimetrias em membros inferiores. [Investigations on motor and postural control in asymmetries in lower limbs]. (Doctor Degree), Universidade do São Paulo, São Paulo - Brasil.

Martins L, Signoretti A, Oliveira L, Lucena G (2009) Avaliação goniométrica da articulação do quadril em ginastas rítmicas da cidade de Natal/RN. [Goniometric evaluation of the hip joint in rhythmic gymnasts of the city of Natal/RN]. Revista de Ciência \& Saúde, special.

McGuigan M (2014) Evaluation athletic capacities. In D Joyce, D Lewindon (eds) High Performance Training for Sports. Unites States of America: Human Kinetics.

Miletić D, Katić R, Maleš B (2004) Some anthropologic factors of performance in rhythmic gymnastics novices. Collegium Antropologicum 28(2): 727-737.

Miletić D, Sekulic D, Wolf-Cvitak J (2004) The leaping performance of 7-year-old novice rhythmic gymnasts is highly influenced by the condition of their motor abilities. Kinesiology 36(1): 35-43.

Palmer HC (2003) Teaching Rhythmic Gymnastics: A Developmentally Appropriate Approach, Vol. 1. Champaign, IL: Human Kinetics.

Polat S, Günay M (2016) Comparison of Eight Weeks Rhythmic Gymnastics, Pilates and Combined Training in Terms of Some Physical, Physiological and Motoric 
Parameters. International Journal of Human Movement and Sports Sciences 4(4): 6169.

Poliszczuk T, Brod D (2010) Somatic constitution and the ability to maintain dynamic body equilibrium in girls practicing rhythmic gymnastics. Pédiatrie Endocrinology, Diabetes and Metabolism. 16(2): 94-99.

Radaš J, Bobić T (2011) Posture in top-level Croatian rhythmic gymnasts and non-trainees. Kinesiology 43(1): 64-73.

Román M, Campo V, Solana R, Martín J (2012) Perfil y diferencias antropométricas y físicas de gimnastas de tecnificación de las modalidades de artística y rítmica. [Profile and anthropometric and physical differences of technification gymnasts of artistic and rhythmic modalities]. Retos. Nuevas tendencias en Educación Física, Deporte y Recreación 21: 58-62.

Rutkauskaite R, Skarbalius A (2009) Training and sport performance of the 11-12 year old athletes in rhythmic gymnastics. Sportas 1(72): 107-115.

Rutkauskaite R, Skarbalius A (2011) Interaction of training and performance of 13-14years-old athletes in rhythmic gymnastics. Sportas 3(82): 29-36.

Sands W, McNeal J, Penitente G, Murray S, Nassar L, Jemni M, Mizuguchi S, Stone M (2016) Stretching the spines of gymnasts: a review. Sports Med. 46(3): 315-327.

Santos AB (2011) Flexibilidade e Força em Ginástica Rítmica: Avaliação de ginastas juniores portuguesas.[Flexibility and Strength in Rhythmic Gymnastics: Evaluation of Portuguese Junior Gymnasts]. (Master), University of Porto, Porto.

Stadnik AM, Ulbricht L, Perin A, Ripka WL (2010) Avaliação da performance relacionada aos componentes equilíbrio, força e flexibilidade de meninas praticantes de Ginástica Rítmica. [Performance evaluation related to balance, strength and flexibility components of girls practicing rhythmic gymnastics]. EFDeportes, 15. Available at $\mathrm{http}: / / \mathrm{www} . e f d e p o r t e s . c o m / e f d 145 /$ avaliacao-de-meninas-praticantes-de-ginasticaritmica.htm.

Teixeira LA (2001) Prática diferencial e assimetrias lateriais em tarefas motoras relacionadas ao Futebol Lateralidade e comportamento motor: assimetrias laterais de desempenho e transferência interlateral de aprendizagem [Differential practice and lateral asymmetries in motor tasks related to Soccer Laterality and motor behavior: lateral asymmetries of performance and interlateral learning transfer], 69-79. São Paulo: Escola de Educação Física e Esporte da Universidade de São Paulo.

Teixeira LA, Paroli R (2000) Assimetrias Laterais em Ações Motoras: Preferência Versus Desempenho. [Lateral Asymmetries in Motor Actions: Preference Versus Performance]. Motriz 6(1): 1-8.

Teixeira LA, Silva MV, Carvalho M (2003) Reduction of lateral asymmetries in dribbling: the role of bilateral practice. Laterality 8(1): 53-65.

Volpi da Silva L, Lopez L, Costa MC, Gomes Z, Matsushigue K (2008) Avaliação da flexibilidade e análise postural em atletas de ginástica rítmica desportiva: flexibilidade e postura na ginástica rítmica. [Evaluation of flexibility and postural analysis in athletes of Sports Rhythmic Gymnastics: Flexibility and Posture in Rhythmic Gymnastics]. Revista Mackenzie de Educação Física e Esporte 7(1): 5968.

Weineck J (2003) Treinamento Ideal, Vol. 9. São Paulo: Manole.

Zaidi ZF (2011) Body asymmetries: incidence, etiology and clinical implications. Australian Journal of Basic and Applied Sciences 5( 9): 2157-2191. 